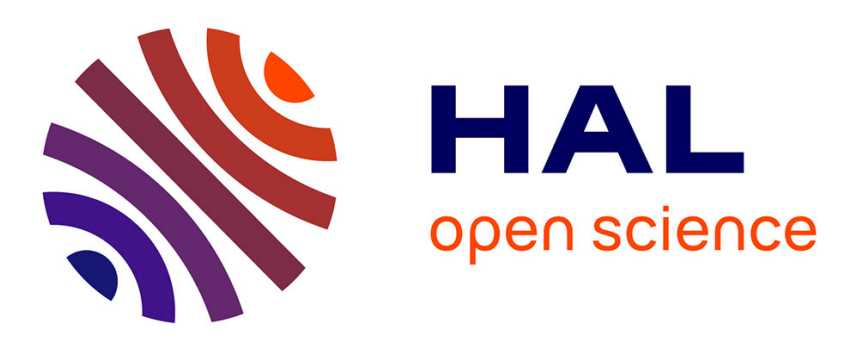

\title{
Characterization of Model Spread in PMIP2 Mid-Holocene Simulations of the African Monsoon
}

Weipeng Zheng, Pascale Braconnot

\section{To cite this version:}

Weipeng Zheng, Pascale Braconnot. Characterization of Model Spread in PMIP2 Mid-Holocene Simulations of the African Monsoon. Journal of Climate, 2013, 26 (4), pp.1192-1210. 10.1175/JCLI-D12-00071.1 . hal-03019441

\section{HAL Id: hal-03019441 https://hal.science/hal-03019441}

Submitted on 9 Jun 2021

HAL is a multi-disciplinary open access archive for the deposit and dissemination of scientific research documents, whether they are published or not. The documents may come from teaching and research institutions in France or abroad, or from public or private research centers.
L'archive ouverte pluridisciplinaire HAL, est destinée au dépôt et à la diffusion de documents scientifiques de niveau recherche, publiés ou non, émanant des établissements d'enseignement et de recherche français ou étrangers, des laboratoires publics ou privés. 


\title{
Characterization of Model Spread in PMIP2 Mid-Holocene Simulations of the African Monsoon
}

\author{
WEIPENG ZHENG \\ Laboratoire des Sciences du Climat et de l'Environnement, UMR 1572 CEA-CNRS-UVSQ, Gif-sur-Yvette, France, and State Key \\ Laboratory of Numerical Modeling for Atmospheric Sciences and Geophysical Fluid Dynamics, Institute of Atmospheric Physics, \\ Chinese Academy of Sciences, Beijing, China \\ PASCALE BRACONNOT \\ Laboratoire des Sciences du Climat et de l'Environnement, UMR 1572 CEA-CNRS-UVSQ, Gif-sur-Yvette, France
}

(Manuscript received 29 January 2012, in final form 1 August 2012)

\begin{abstract}
Simulations of the West African monsoon (WAM) for the present-day climate ( $0 \mathrm{ka})$ and the mid-Holocene (6 ka) using the coupled models from the Paleoclimate Modelling Intercomparison Project phase 2 (PMIP2) are assessed in this study. The authors first compare the ensemble simulations with modern observations and proxy estimates of past precipitation, showing that the PMIP2 model median captures the basic features of the WAM for $0 \mathrm{ka}$ and the changes at $6 \mathrm{ka}$, despite systematic biases in the preindustrial (PI) simulations and underestimates of the northward extent and intensity of precipitation changes.

The model spread is then discussed based on a classification of the monsoonal convective regimes for a subset of seven coupled models. Two major categories of model are defined based on their differences in simulating deep and moderate convective regimes in the PI simulations. Changes in precipitation at $6 \mathrm{ka}$ are dominated by changes in the large-scale dynamics for most of the PMIP2 models and are characterized by a shift in the monsoonal circulation toward deeper convective regimes. Consequently, changes in the total precipitation at $6 \mathrm{ka}$ depend on the changes in convective regimes and the characteristics of these regimes in the PI simulations. The results indicate that systematic model biases in simulating the radiation and heat fluxes could explain the damping of the meridional temperature gradient over West Africa and thereby the underestimation of precipitation in the Sahel-Sahara region.
\end{abstract}

\section{Introduction}

Variability in annual precipitation in West Africa is dominated by the seasonal and interannual variations of the monsoon rainfall during boreal summer [the West African monsoon (WAM)]. Following the seasonal migration of the intertropical convergence zone (ITCZ), the WAM brings the rainfall maxima to the north of the ITCZ, leading to the rainy season in these regions. These seasonal variations are tied to the large-scale circulation resulting from the large-scale land-sea thermal contrast, which may or not override the low-level or local factors linked to surface processes or local hydrology (Xue et al.

Corresponding author address: Weipeng Zheng, LASG, Institute of Atmospheric Physics, Chinese Academy of Sciences, No. 40 Huayanli, Chaoyang District, 10029 Beijing, China.

E-mail: zhengwp@mail.iap.ac.cn
2010). Several studies show that general circulation models (GCMs), when forced with prescribed sea surface temperature (SST), have some skill in reproducing the pronounced precipitation trend that prevailed during the 1970s in these regions (Giannini et al. 2003; Zhou and $\mathrm{Yu}$ 2006). However, when the ocean is coupled to the atmosphere, these models tend to overestimate the correlation between West African precipitation and interannual fluctuations induced by teleconnections between El Niño events and the WAM circulation (Jolly et al. 1998b; Zhao et al. 2007). Other factors, such as variations in the Atlantic Ocean circulation, affect the mean location of the rain belt over the tropical Atlantic, thereby influencing West African rainfall (Zhao et al. 2005). The model complexity and resolution required to represent the different aspects of the WAM have not yet been established. Available GCM simulations do not have the required resolution to model local factors, such 
as the orography, which is of limited amplitude in West Africa but plays a role in the development of the African heat low (Cook 1999) and in the triggering and organization of the convection. The link between boundary layer processes and interannual rainfall, which is important for research into the climate of semiarid regions of the Sahel, is not yet understood (Nicholson 2000). To improve our understanding of the interactions between climate dynamics and land surface variability changes requires documenting the complicated balance between surface-driven variation and large-scale flow patterns (Dolman et al. 1997; Bony and Dufresne 2005).

Despite recent progress in the monitoring and understanding of the WAM within the framework of the African Monsoon Multidisciplinary Analysis (AMMA; http://amma-international.org/), there are still large uncertainties in projections of future climate in this region, such that even the sign of future precipitation change is uncertain (Solomon et al. 2007). Consequently, it is necessary to consider other climatic periods to gain a better understanding of the sensitivity of the WAM precipitation to different forcings. Evidence from pollen data, past lake levels, and other proxy records suggest a much wetter period in the Sahel and Sahara regions from the early Holocene to the mid-Holocene (Anderson et al. 1988; Jolly et al. 1998b; Gasse 2002; Kohfeld et al. 2005; Lézine et al. 2011; Bartlein et al. 2011). This wet period was triggered by an enhanced seasonal cycle of insolation induced by slow variations in Earth's orbital parameters (Kutzbach and Otto-Bliesner 1982; Kutzbach and Guetter 1986; Kutzbach and Liu 1997; Joussaume et al. 1999). Although this wet period cannot be considered as an analog for future climate change (Mitchell 1990), it provides a test of our understanding of the seasonal evolution of the monsoon system and of its sensitivity to global and local factors. The mid-Holocene period has been established as a benchmark period for climate models by the Paleoclimate Modelling Intercomparison Project phase 1 (PMIP1) (Joussaume and Taylor 1995). Previous studies (Joussaume et al. 1999) have shown that simulations relying on SST prescribed at modern values underestimated the increased precipitation resulting from changes in insolation and that ocean and vegetation feedbacks were needed to produce enhanced precipitation closer to proxy reconstructions (Braconnot et al. 2004).

Simulations performed as part of PMIP2 include both ocean-atmosphere and ocean-atmosphere-vegetation models (Braconnot et al. 2007a). This set of simulations confirms previous findings. Improvements in the SST bias contribute to an improved simulation of the monsoon at $6 \mathrm{ka}$ (Ohgaito and Abe-Ouchi 2009). In particular, the increased SST gradient that built up across $5^{\circ} \mathrm{N}$ in the tropical Atlantic in response to the increased insolation in the Northern Hemisphere favors a position of the ITCZ farther north than at present, together with a northward shift and intensification of the West African rain belt (Zhao et al. 2005; Braconnot et al. 2007b). The simulations have also revealed that the vegetation feedback may be weaker than initially thought and that the interactions between monsoon, and vegetation and soil moisture may not be adequately represented in the Sahel transition region. There is also a wide spread in the results, with precipitation increase ranging from 2 to $4 \mathrm{~mm} \mathrm{day}^{-1}$ on average over the Sahel region (Braconnot et al. 2007a). Some of the differences have been attributed to differences in the desert albedo (Braconnot et al. 2007b). However, other factors, such as model parameterizations (convection scheme, clouds, boundary layers, and surface hydrology), should be analyzed in more depth.

Previous analyses of mid-Holocene simulations also clearly show that a full assessment of the realism of past simulations requires comparison of simulations of the modern climate and past changes with modern observations and proxy reconstructions, respectively (Joussaume et al. 1999). The location of the simulated modern ITCZ is likely to be an important factor in determining the location of the change in precipitation in the midHolocene, even though there is not necessarily a link between the northward extent of the ITCZ and the magnitude of precipitation changes (Joussaume et al. 1999). Similarly, depending on the structure of the largescale circulation over West Africa, the regions that are most affected by the insolation changes may vary from one model to the other, favoring north-south or eastwest gradients in the temperature and precipitation changes (Braconnot et al. 2002).

The objective of the present work is to revisit the results of PMIP2 simulations over Africa using two approaches. The first approach considers the ensemble of simulations in order to determine how well the PMIP2 models reproduce some of the basic features of the summer monsoon precipitation; the spread among the different model results is then discussed on a regional basis, considering the modern climate, the simulated changes for the midHolocene, and the mechanisms. The second objective is to understand model differences by considering model characteristics for present-day climate and their sensitivities to the insolation change. We adopt a classification into convective regimes, following Bony et al. (2004), to determine if systematic differences appear between the different model results depending on the distribution of convection over West Africa. This analysis emphasizes the comparison of atmospheric processes, which provides an interesting complement to the geographical 
TABLE 1. List of PMIP2 models and references. Model names not expanded in text are as follows: Commonwealth Scientific and Industrial Research Organisation Mark, version 3 (CSIRO Mk3); Earth System Model of Intermediate Complexity (EMIC) Climate deBilt-Coupled Large-Scale Ice Ocean-Vegetation Continuous Description (ECBilt-CLIO-VECODE); Max Planck Institute Ocean Model (MPI-OM); Lund-Potsdam-Jena dynamic global vegetation model (LPJ); Fast Ocean Atmosphere Model (FOAM); Goddard Institute for Space Studies Model E (GISS-E); IPSL Coupled Model, version 4 (CM4); MRI Coupled General Circulation Model (CGCM); the Met Office model run at Bristol University (UBRIS); and third climate configuration of the Met Office Unified Model (HadCM3).

\begin{tabular}{|c|c|c|c|c|}
\hline Model name in PMIP2 database & Short name & $\mathrm{OA}$ & OAV & Reference \\
\hline CCSM3* & CCSM3 & $\mathrm{X}$ & & Otto-Bliesner et al. 2006 \\
\hline CSIRO Mk3L-1.0 & CSIRO1.0 & $\mathrm{X}$ & & Phipps 2006 \\
\hline CSIRO Mk3L-1.1 & CSIRO1.1 & $\mathrm{X}$ & & Phipps 2006 \\
\hline ECBilt-CLIO-VECODE & ECBILT & $\mathrm{X}$ & $\mathrm{X}$ & Renssen et al. 2005 \\
\hline ECHAM5-MPI-OM1 & ECHAM5 & $\mathrm{X}$ & & Jungclaus et al. 2006 \\
\hline ECHAM53-MPI-OM127-LPJ & ECHAM5-LPJ & $\mathrm{X}$ & $\mathrm{X}$ & Marsland et al. 2003 \\
\hline FGOALS-1.0g* & FGOALS & $\mathrm{X}$ & & Yu et al. 2004 \\
\hline FOAM* & FOAM & $\mathrm{X}$ & $\mathrm{X}$ & Jacob et al. 2001 \\
\hline GISS-E & GISS & $\mathrm{X}$ & & Schmidt et al. 2006 \\
\hline IPSL CM4* & IPSL & $\mathrm{X}$ & & Marti et al. 2010 \\
\hline MIROC $3.2 *$ & MIROC & $\mathrm{X}$ & & K-1 Model Developers 2004 \\
\hline MRI CGCM2.3.4fa* & MRIfa & $\mathrm{X}$ & $\mathrm{X}$ & Yukimoto et al. 2006 \\
\hline MRI CGCM2.3.4nfa* & MRInfa & $\mathrm{X}$ & $\mathrm{X}$ & Yukimoto et al. 2006 \\
\hline UBRIS-HadCM3M2 & HadCM3 & $\mathrm{X}$ & $\mathrm{X}$ & Gordon et al. 2000 \\
\hline
\end{tabular}

* Model used in the classification of the dynamical regime.

comparison made in the first part. It also provides a complementary view to Braconnot et al. (2000), who analyzed the relative contributions of the different fluxes affecting the atmospheric energy budget in the set of PMIP1 simulations with atmosphere-only models and showed that differences between PMIP1 simulations reflect differences in model parameterizations, including surface processes and clouds.

The manuscript is organized as follows: Section 2 presents the PMIP2 simulations for 0 and $6 \mathrm{ka}$ as estimated from the PMIP2 ensemble. Section 3 describes the spread in PMIP2 model results for different convective regimes. Finally, a discussion of the results and the main conclusions are presented in section 4 .

\section{Preindustrial and mid-Holocene climate as estimated from the PMIP2 ensemble}

\section{a. Models and data}

The version of the PMIP2 database used in this study includes 14 mid-Holocene (6 ka) simulations performed with coupled ocean-atmosphere (OA) models (Table 1). Some modeling groups also used ocean-atmospherevegetation (OAV) models, but these six OAV model versions are slightly different from their OA counterparts, so it is not possible to compare the pairs of OA and OAV simulations directly to diagnose the vegetation feedback (Braconnot et al. 2007b). Detailed model descriptions can be found on the PMIP2 website (http:// pmip2.lsce.ipsl.fr/). The simulations were run following the PMIP2 protocol. The control experiment $(0 \mathrm{ka})$ is a preindustrial climate simulation for which trace gases are set to the 1750 values. The mid-Holocene experiment considers changes in Earth's orbital parameters and trace gases (Braconnot et al. 2007a). The PMIP2 database includes 100 -yr-long monthly means corresponding to a period after model adjustment to the new forcing. For all the model simulations we computed the monthly-mean climatology from these $100 \mathrm{yr}$ and used individual summer months in the classification into convective regimes.

We first consider all the 20 available simulations (Table 1) for the model ensemble without differentiating between OA and OAV simulations. For the diagnoses of convective regimes in section 3 , we consider only a subset of seven simulations (marked with an asterisk in Table 1), for which the PMIP2 database contained the necessary variables.

Two independent reanalysis datasets, the National Centers for Environmental Prediction (NCEP) (Kalnay et al. 1996) and the 40-yr European Centre for Medium Range Weather Forecasts (ECMWF) Re-Analysis (ERA-40; Uppala et al. 2005), are used to assess the largescale circulation features and African monsoon dynamics reproduced by the coupled models. Several drawbacks have been identified with these datasets over Africa. In particular, ERA-40 rainfall and surface temperature are affected by a discontinuity in 1978 when assimilation of reliable satellite data began (Kållberg 1997). The NCEP reanalysis generally underestimates the rainfall amount during the rainy season in tropical Africa, and three artificial abrupt shifts are found that may be related to 
problems in the data assimilation and the availability of observations (Poccard et al. 2000). However, these reanalyses provide a consistent picture of the monsoonal circulation and we only consider the mean seasonal cycle here. Because of the known unreliability in both reanalyses, we also consider the rainfall and surface air temperature (TAS) from the Climatic Research Unit (CRU) dataset over the continent (Mitchell and Jones 2005). In addition, the radiation and heat fluxes from the Earth Radiation Budget Experiment (ERBE) (Barkstrom 1984) at the top of atmosphere (TOA) and the International Satellite Land-Surface Climatology Project (ISLSCP) (Smith 1998) at the surface are used to validate the representation of these fluxes in the different control simulations.

\section{b. Simulated temperature and precipitation in West Africa}

The PMIP2 simulations are considered as an ensemble in order to discuss the characteristics of the West African monsoon in terms of TAS, precipitation, sea level pressure (SLP), and radiation and heat fluxes at TOA and the surface for both the 0- and 6-ka simulations. A best estimate of the simulated climate periods is provided by the model median for different variables (Figs. 1-3). We consider the median rather than the ensemble mean because the number of simulations is small and the model simulations are not symmetrically distributed around the ensemble mean. With this solution, outliers have less weight in the analysis. The median was estimated at each grid point of a $1^{\circ} \times 1^{\circ}$ grid over West Africa. Because of the different resolutions in the PMIP2 coupled models, a bilinear interpolation was first applied to interpolate different climate variables onto the common $1^{\circ} \times 1^{\circ}$ grid. At each grid point and for each variable, the values of model simulations were then sorted from minimum to maximum in order to extract the median value as well as the first and the third quartiles. These quartiles are used to define the interval around the median where $50 \%$ of the simulations can be found, as well as the error bars in Figs. 1-3. Since a different model may be chosen as the median at each grid point, there is no inherent direct physical linkage between different fields: they only provide orders of magnitude and the large-scale patterns showing how well the PMIP2 ensemble captures the climatology over West Africa.

The summer rain belt maximum for the model median for $0 \mathrm{ka}$ is located around $8^{\circ} \mathrm{N}$ (Fig. 1b), in agreement with the CRU climatology (Fig. 1a). The rain belt corresponds to the location of maximum ascent at $500 \mathrm{hPa}$, while descending air controls most of the Sahara region. The model median captures this feature well but the simulated precipitation is slightly underestimated between $0^{\circ}$ and $10^{\circ} \mathrm{N}$ (Fig. 1c). This is consistent with Cook and Vizy (2006), who show that most climate models fail to capture the three precipitation maxima located on the west coast, over the eastern portion of the Guinea coast and over the Ethiopian highlands, respectively. Figure 2 shows the corresponding TAS and SLP. Although the TAS and SLP are underestimated over West Africa (Fig. 2c), the African heat low over the western Sahara is captured by the model median (Fig. 2b). However, the model spread is large for these variables, particularly along the Sahel region and in the Gulf of Guinea for the precipitation (Fig. 1d) and in the Sahara for the TAS (Fig. 2d).

The mid-Holocene insolation forcing increases TAS in the Sahara and reinforces the African heat low, thereby enhancing the north-south pressure gradient (Fig. 2e) and the northward penetration of the African monsoon flow into the Sahara (Fig. 1e). This feature has been discussed widely in the literature (e.g., Anderson et al. 1988; Joussaume et al. 1999). The PMIP2 model median shows stronger convection developing in the Sahel and extending northward into the Sahara, increasing the precipitation in the Sahel and in the southern part of Sahara but decreasing it along the Gulf of Guinea (Fig. 1e). The TAS decreases where precipitation increases (Fig. 2e) because the increased cloud associated with the convection reflects solar radiation back to space (de Noblet et al. 1996; Zhao et al. 2005). Enhanced local hydrological recycling may also contribute to surface cooling. As shown in Fig. 1f, the model spread for the precipitation widens in North Africa and around $10^{\circ} \mathrm{N}$, implying different representations of northward shift of the rain belt among the PMIP2 models. The model spread for TAS also widens around $20^{\circ} \mathrm{N}$, which is consistent with the changes found for precipitation (Fig. 2f).

Pollen reconstructions from Jolly et al. (1998a) indicate much wetter conditions during the mid-Holocene up to $23^{\circ} \mathrm{N}$. However, Joussaume et al. (1999) concluded that the northward extent and magnitude of the annualmean precipitation in the mid-Holocene was underestimated by PMIP1 atmosphere-only simulations. Using a lake model, Coe and Harrison (2002) obtained a $>30 \%$ underestimate of the maximum extent of Lake Chad. Braconnot et al. (2007a) reported that the PMIP2 coupled ocean-atmosphere simulations gave improved results for the zonal-mean change in precipitation. However, even though it produces twice the PMIP1 precipitation north of $18^{\circ} \mathrm{N}$, the PMIP2 ensemble still underestimates the rainfall by about $25 \%-30 \%$. Peyron et al. (2006) used two different methods to reconstruct precipitation from pollen data and provided a more regional assessment of model results in data-rich regions. We computed the annual-mean precipitation averaged 

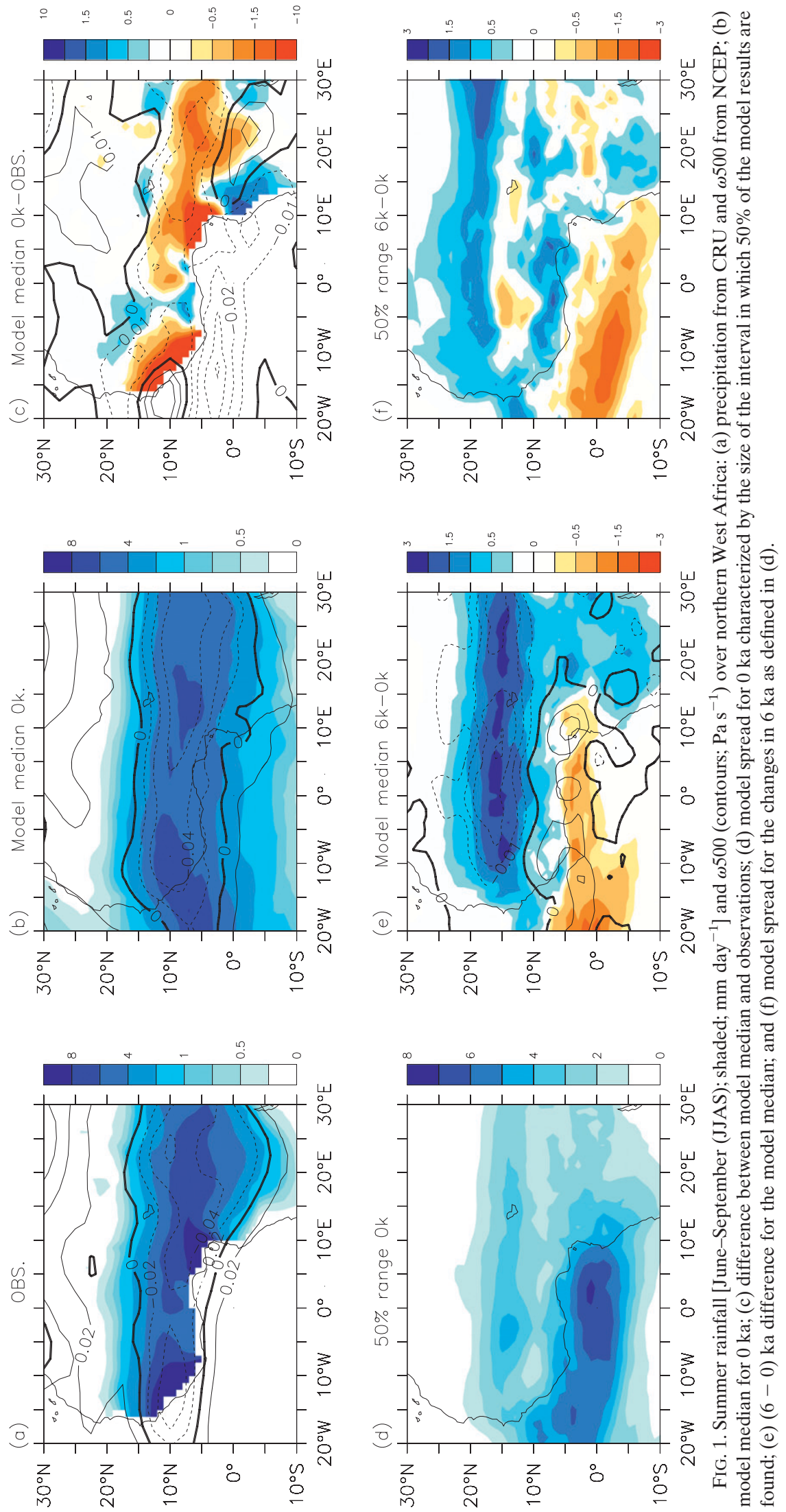

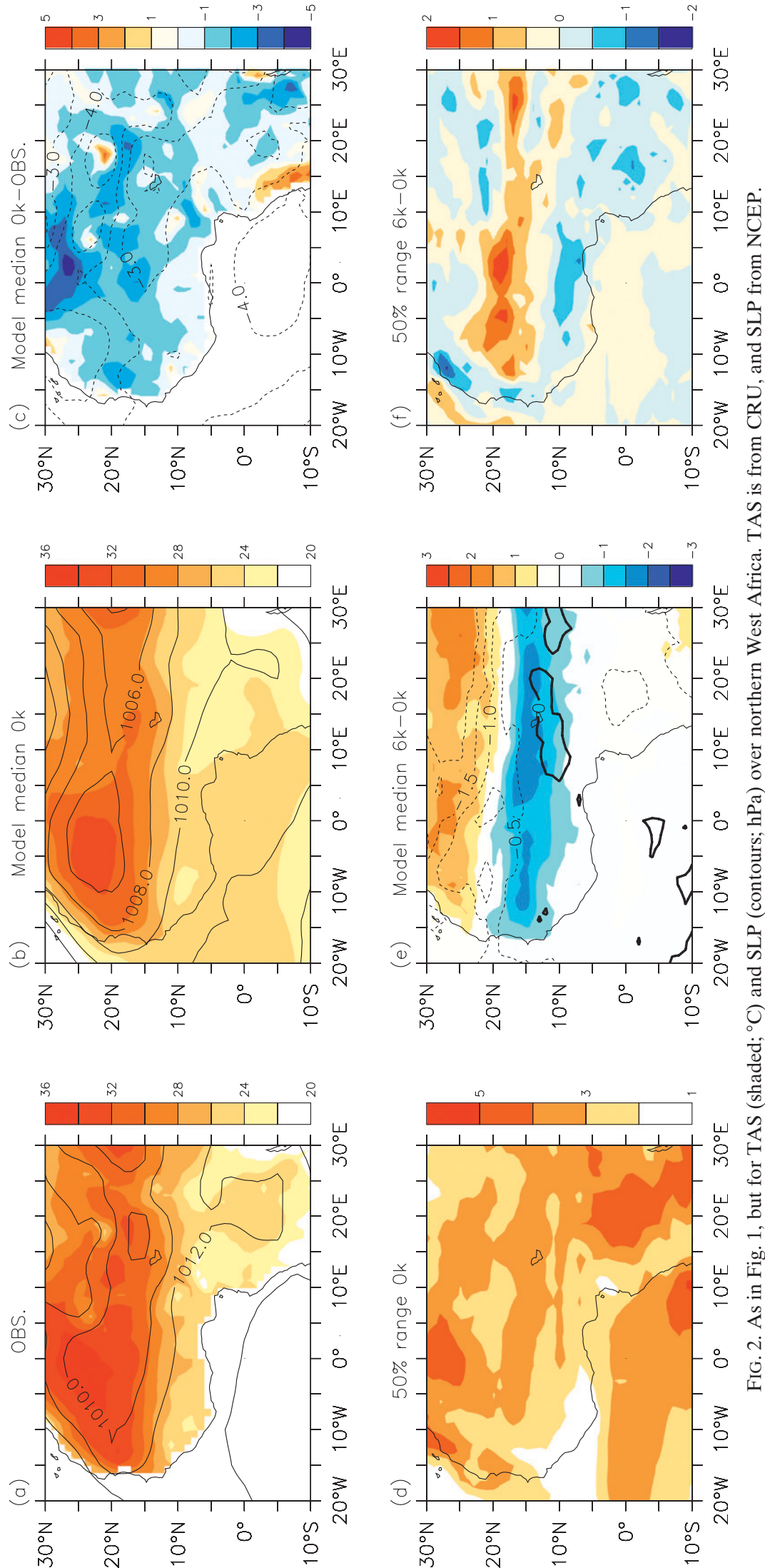
(a) Oka
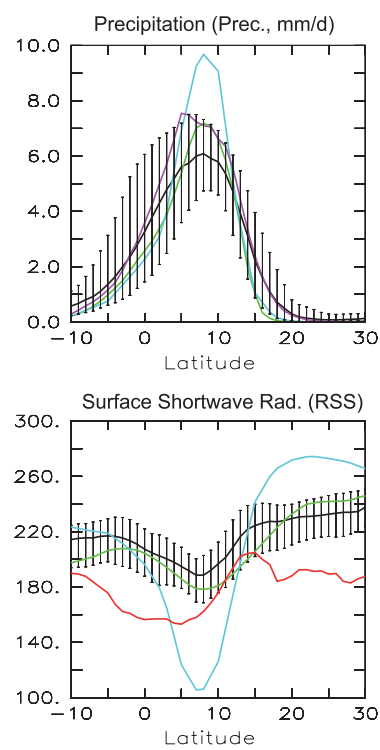

(b) 6ka-0ka
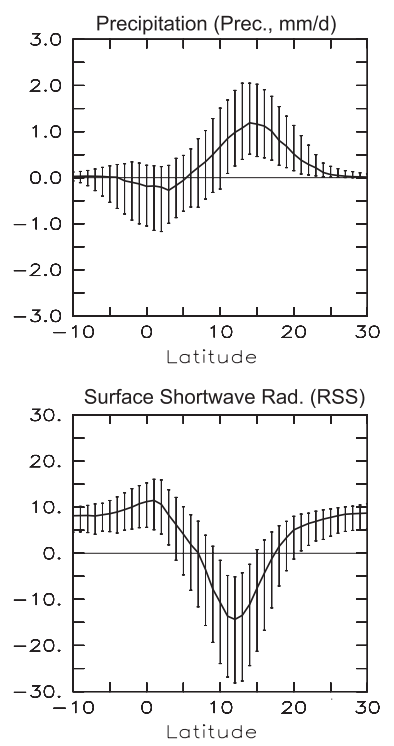
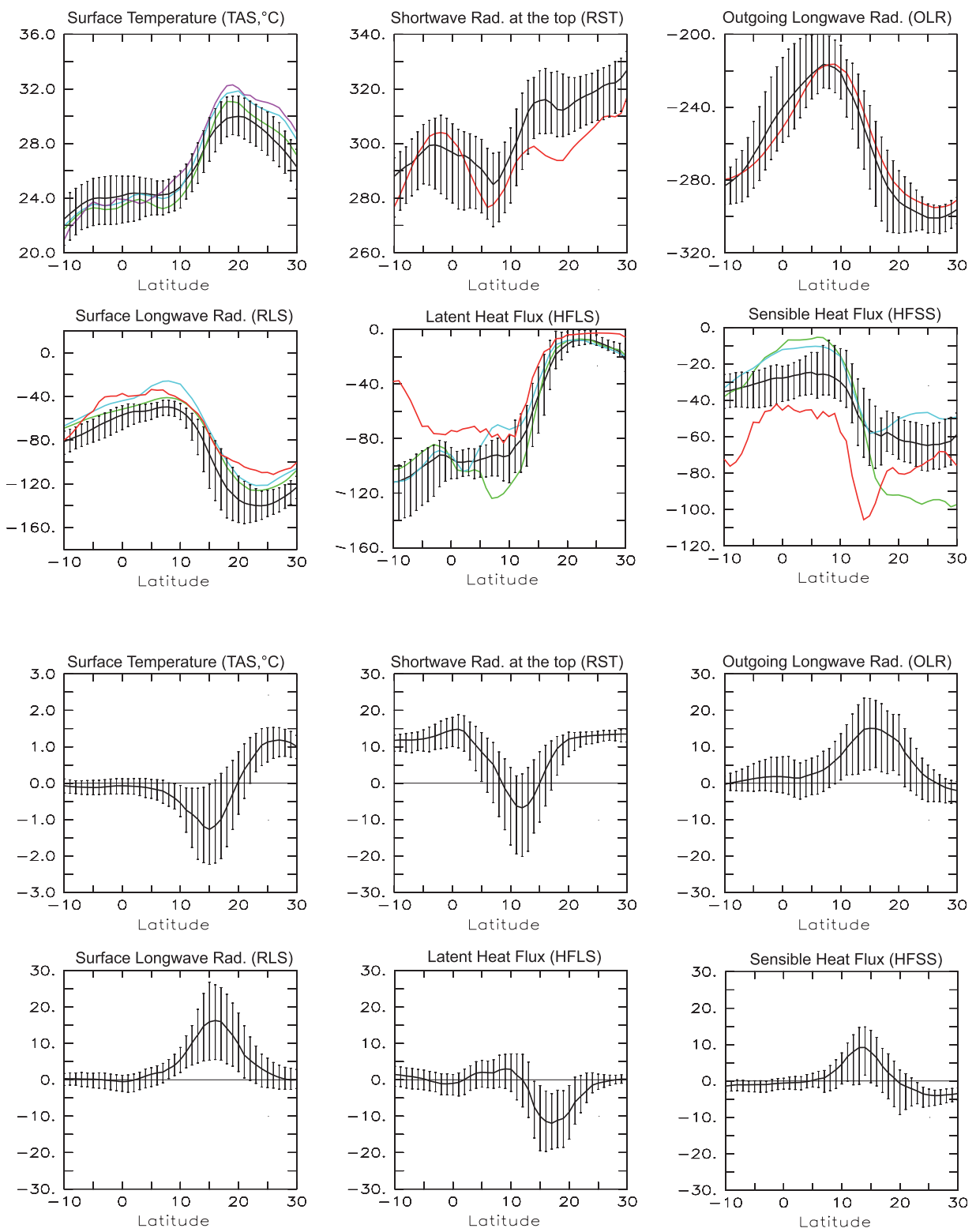

FIG. 3. Meridional distribution (zonal averages between $20^{\circ} \mathrm{W}$ and $30^{\circ} \mathrm{E}$ ) plots of (left to right) (first and third rows) precipitation $\left(\mathrm{mm} \mathrm{day}{ }^{-1}\right)$, TAS $\left({ }^{\circ} \mathrm{C}\right), \mathrm{RST}$, OLR; and (second and fourth rows) RSS, RLS, HFLS, and HFSS: (a) 0 ka and (b) $(6-0)$ ka. Black lines are for the PMIP2 model median, and the bars represent the range of 50\% model spread; red lines in the panels of RST and OLR are from ERBE, while in the surface heat flux panels they are from ISLSCP. The green, blue, and purple lines are for NCEP, ERA-40, and CRU, respectively. Units for radiation and heat fluxes are $\mathrm{W} \mathrm{m}^{-2}$, and all fluxes are positive downward.

over the same regions as in their Fig. 2: values for $0 \mathrm{ka}$ and their changes for $6 \mathrm{ka}$ are shown in Table 2. Most of the models overestimate the annual-mean precipitation over the Sahara-Sahel regions $\left(10^{\circ}-20^{\circ} \mathrm{N}, 10^{\circ}-14^{\circ} \mathrm{E}\right)$ and underestimate the amount of precipitation over the eastern Sahara $\left(18^{\circ}-26^{\circ} \mathrm{N}, 20^{\circ}-30^{\circ} \mathrm{E}\right)$ in 0 -ka simulations when compared with CRU data (Table 2). During the mid-Holocene, PMIP2 models produce more than
$100 \mathrm{~mm} \mathrm{yr}^{-1}$ of precipitation change over the SaharaSahel regions, but only two simulations match the 300 $600 \mathrm{~mm} \mathrm{yr}^{-1}$ suggested by the reconstruction data. Over the eastern Sahara, all the PMIP2 simulations produce increased precipitation, with five of them producing an increase between 90 and $400 \mathrm{~mm} \mathrm{yr}^{-1}$, as suggested by the reconstruction (Table 2). Farther south along the equator the precipitation change is positive or 
TABLE 2. Annual precipitation for the preindustrial (PI) simulations (0 ka) and the changes for mid-Holocene [(6 - 0) ka] in the Sahara-Sahel and eastern Sahara regions. The numbers in the parentheses are from the OAV simulations. Units are in millimeters.

\begin{tabular}{|c|c|c|c|c|}
\hline \multirow[b]{2}{*}{ Models } & \multicolumn{2}{|c|}{ Sahara-Sahel $\left(10^{\circ}-20^{\circ} \mathrm{N}, 10^{\circ}-14^{\circ} \mathrm{E}\right)$} & \multicolumn{2}{|c|}{ Eastern Sahara $\left(18^{\circ}-26^{\circ} \mathrm{N}, 20^{\circ}-30^{\circ} \mathrm{E}\right)$} \\
\hline & $0 \mathrm{ka}$ & $(6-0) \mathrm{ka}$ & $0 \mathrm{ka}$ & $(6-0) \mathrm{ka}$ \\
\hline CRU & 284.8 & - & 22.04 & - \\
\hline CCSM3 & 435.6 & 138.7 & 10.32 & 87.39 \\
\hline CSIRO1.0 & 265.4 & 115.2 & 6.793 & 7.18 \\
\hline CSIRO1.1 & 296.8 & 122.4 & 6.33 & 7.23 \\
\hline ECBILT & $601.4(563.6)$ & $45.53(299.2)$ & $243.8(155.8)$ & $48.45(205.1)$ \\
\hline ECHAM5 & 232.4 & 166.0 & 10.99 & 68.57 \\
\hline ECHAM5-LPJ & $384.1(377.6)$ & $143.8(192.6)$ & $27.66(24.66)$ & $6.02(90.0)$ \\
\hline FGOALS & 524.6 & 348.0 & 137.2 & 402.6 \\
\hline FOAM & $1304.0(1255.0)$ & $52.99(63.8)$ & $92.02(77.01)$ & $96.74(122.9)$ \\
\hline GISS & 309.9 & 218.4 & 26.89 & 47.72 \\
\hline IPSL & 93.58 & 55.5 & 1.65 & 1.32 \\
\hline MIROC & 575.5 & 246.3 & 77.16 & 59.57 \\
\hline MRIfa & $132.9(164.6)$ & $100.4(189.5)$ & $1.673(1.623)$ & 1.64 (14.82) \\
\hline MRInfa & $126.6(157.2)$ & $129.1(370.5)$ & $3.545(4.662)$ & 15.14 (109.8) \\
\hline HadCM3 & $615.5(619.6)$ & $201.9(167.4)$ & $33.28(52.14)$ & $20.01(13.37)$ \\
\hline
\end{tabular}

negative, depending on the model. There is a more systematic reduction of precipitation in East Africa, which is consistent with data estimates (Hély et al. 2009). This comparison confirms the overall statement that the ocean feedback strengthens the monsoon response to the insolation forcing in the mid-Holocene, but the precipitation changes are still underestimated. It also highlights that some of the models produce an east-west gradient in precipitation change that is not seen in the data. In addition, those models that produce a precipitation change in better agreement with paleoreconstruction do not necessarily produce the right amount of precipitation in the 0-ka simulation (Table 2) [e.g., Flexible Global Ocean-Atmosphere-Land System Model (FGOALS)]. Thus, in addition to the direct evaluation of precipitation in the different climates, better understanding and evaluation of the processes are needed.

\section{c. Radiation and heat fluxes at TOA and the surface}

Since the rainfall and TAS are zonally distributed, as shown in Figs. $1 b$ and 2b, we further compare the PMIP2 model median for $0 \mathrm{ka}$ with several zonally averaged climatologies in Fig. 3a and consider the link between precipitation, TAS, and the radiation and heat fluxes. Large differences are found between the two reanalyses and the CRU data for precipitation; this is likely to be due to either a lack of observations or differences in the parameterizations. In some regions these differences equal the range of $50 \%$ model spread. It is thus difficult to assess the realism of PMIP2 0-ka simulations fully, particularly in the deep convection region around $10^{\circ} \mathrm{N}$ (Fig. 3a). However, the comparison shows that the PMIP2 model median reproduces the meridional distributions of precipitation, TAS, and the radiation and heat fluxes at TOA reasonably well when compared with the various observational datasets. The northernmost limit of precipitation coincides with the maximum temperature and the location of the minimum of the heat low in the Sahara, as discussed in Braconnot et al. (2000). Compared with the ERBE data, the shortwave radiation at TOA over the Sahara region is overestimated by the model median but the outgoing longwave radiation agrees well [Fig. 3a: shortwave radiation at TOA (RST) and outgoing longwave radiation (OLR)]. At the surface, the model median shows greater shortwave radiation, longwave radiation, and latent heat flux than the ISLSCP satellite data [Fig. 3a: shortwave radiation at surface (RSS), longwave radiation at surface (RLS), and latent heat flux (HFLS)] but a weaker sensible heat flux [Fig. 3a: sensible heat flux (HFSS)]. This may be partially attributed to the fact that the simulations neglect the direct radiative forcing of natural aerosols, which significantly reduce the solar energy reaching the surface (Mallet et al. 2008). Guichard et al. (2009) estimated the net surface radiation in the Sahelian Gourma $\left(15.3^{\circ} \mathrm{N}, 1.5^{\circ} \mathrm{W}\right)$ from ground measurements to be around $120-160 \mathrm{~W} \mathrm{~m}^{-2}$ in late boreal summer. Taking this value as representative of the zonal mean, the surface radiative budget in the model median of $130 \mathrm{~W} \mathrm{~m}^{-2}$ is within the estimated range but about $30 \mathrm{~W} \mathrm{~m}^{-2}$ lower than the upper limit; this results mainly from greater longwave emission than in the observations. The meridional temperature gradient is also underestimated between $0^{\circ}$ and $20^{\circ} \mathrm{N}$ in the PMIP2 model median (Fig. 3a: TAS). This translates into a smaller SLP gradient between the Gulf of Guinea and the Sahel (Fig. 2c) and could explain a lower than observed lowlevel moisture flux and therefore an underestimate of 
the intensity of the rain belt (Fig. 3a: precipitation) in the model median compared with observations. The inverse variation of the zonal distribution of precipitation and temperature is mirrored in the latitudinal variations of the HFLS and HFSS at the surface (Fig. 3a: HFSS and HFLS) that is also linked to the soil moisture (Fontaine et al. 2007).

The signature of the northward shift of the rain belt in the different fluxes during the mid-Holocene is depicted in the zonal means plotted in Fig. 3b. The maximum cooling coincides with the maximum precipitation increase and the northern limit of precipitation coincides with the largest surface warming. The cloud albedo effects at TOA and the surface are greatest just to the south of the maximum change in precipitation (Fig. 3b: RST and RSS), while the increased trapping of longwave radiation in the atmosphere is greatest just to the north of it (Fig. 3b: OLR). Since the surface longwave radiation and sensible heat flux are linked to TAS, the changes in these two variables resemble the change in TAS (Fig. 3b: RLS and HFSS). The change in latent heat flux broadly follows the precipitation change (Fig. 3b: HFLS). The maximum change occurs just to the north of the maximum change in precipitation. The increased atmospheric moisture content explains the increased greenhouse gas effect between $15^{\circ}$ and $20^{\circ} \mathrm{N}$.

Note that, even though the net changes in shortwave radiation at TOA and the surface are similar north of $15^{\circ} \mathrm{N}$ and south of $5^{\circ} \mathrm{N}$, the temperature increases in the Sahara region but remains as for 0 ka over the ocean (south of $5^{\circ} \mathrm{N}$ ) (Fig. 3b: TAS). The thermal inertia of the ocean and the fact that the changes in surface fluxes are balanced by changes in the divergence of the oceanic heat transport explain these different responses over land and ocean. Such changes enhance the SLP gradients, the northward shift and intensification of the low-level moisture flux, and thus the precipitation over land.

\section{Model spread as a function of convective regimes}

\section{a. 3D structure of the West African monsoon for 0 and $6 \mathrm{ka}$}

Only seven OA simulations of the models marked with an asterisk in Table 1 are used in this section, because they provide the vertical velocity at $500 \mathrm{hPa}(\omega 500)$ and the variables necessary for the study of convective regimes. These seven simulations show a large spread of precipitation over the Sahara-Sahel and the eastern Sahara regions at $0 \mathrm{ka}$ (Table 2), in which some extreme simulations can be identified; for example, FOAM has too much monsoonal precipitation in the Sahara-Sahel region, while L'Institut Pierre-Simon Laplace (IPSL) has little rainfall in both regions in Table 2. The model spread of precipitation changes at $6 \mathrm{ka}$ also covers the range of model results with FGOALS and FOAM simulating changes of precipitation within the range as estimated by the reconstructions. The model spread of precipitation is linked with the surface characteristics and fluxes simulated by each model, which are part of the complex threedimensional (3D) atmospheric circulation over West Africa (Janicot 1992). Figure 4 provides a synthesis of the $3 \mathrm{D}$ monsoon circulation inferred from the vertical velocity and the location of the atmospheric jet as in Nicholson (2009). The core of the rain belt around $8^{\circ} \mathrm{N}$ (Figs. 1a, 3a) corresponds to the region of deep convection with vertical velocity between -0.08 and $-0.05 \mathrm{~Pa} \mathrm{~s}^{-1}$, as shown in the two reanalysis datasets (Fig. 4a). All the models reproduce this feature, even though the location and strength of the ascending core vary from one model to another (Fig. 4a). Only a subset of models captures the shallower convection near $20^{\circ}$ and $5^{\circ} \mathrm{N}$. This feature is strongly tied to differences in the model convection schemes that affect the meridional temperature gradients. It is triggered by the differences of heat fluxes between the deep convection of the ITCZ and the dry convection of the Sahara heat low (Thorncroft and Blackburn 1999). The red and black solid lines in Fig. 4 show the locations for the core of the African easterly jet (AEJ; red) in the middle troposphere and of the tropical easterly jet (TEJ; black) in the upper troposphere in the present-day climate. The locations of the jet cores were estimated using the zonal winds longitudinally averaged between $10^{\circ} \mathrm{W}$ and $10^{\circ} \mathrm{E}$. In the reanalyses, the AEJ is located around $15^{\circ} \mathrm{N}$ at a latitude that bounds the northern limit of deep convection, while the TEJ lies at $8^{\circ} \mathrm{N}$ for NCEP and $10^{\circ} \mathrm{N}$ for ERA-40 (Fig. 4a). Most of the PMIP2 models capture the location of the TEJ in the upper troposphere within the range of the reanalyses, but the AEJ shows a large spread from $10^{\circ}$ to $22^{\circ} \mathrm{N}$. As discussed by Cook (1999), this reflects the model spread in simulating the meridional temperature gradient between the equator and northern tropics. The intermodel differences in the locations of the AEJ thus reflect the large spread of TAS and latent heat release in the ITCZ (Fig. 3a).

Figure $4 \mathrm{~b}$ shows that the most significant change for $6 \mathrm{ka}$ is the enhancement of the deep convection in northern Sahel and southern Sahara. The location of the TEJ (black dash) does not change much for the models, while the AEJ (red dash) shows a consistent northward shift. The increased latent heat release in the deep convection region enhances the meridional temperature gradient and favors the northward shift of the AEJ that has been shown in atmosphere-only sensitivity experiments (Texier et al. 2000). 

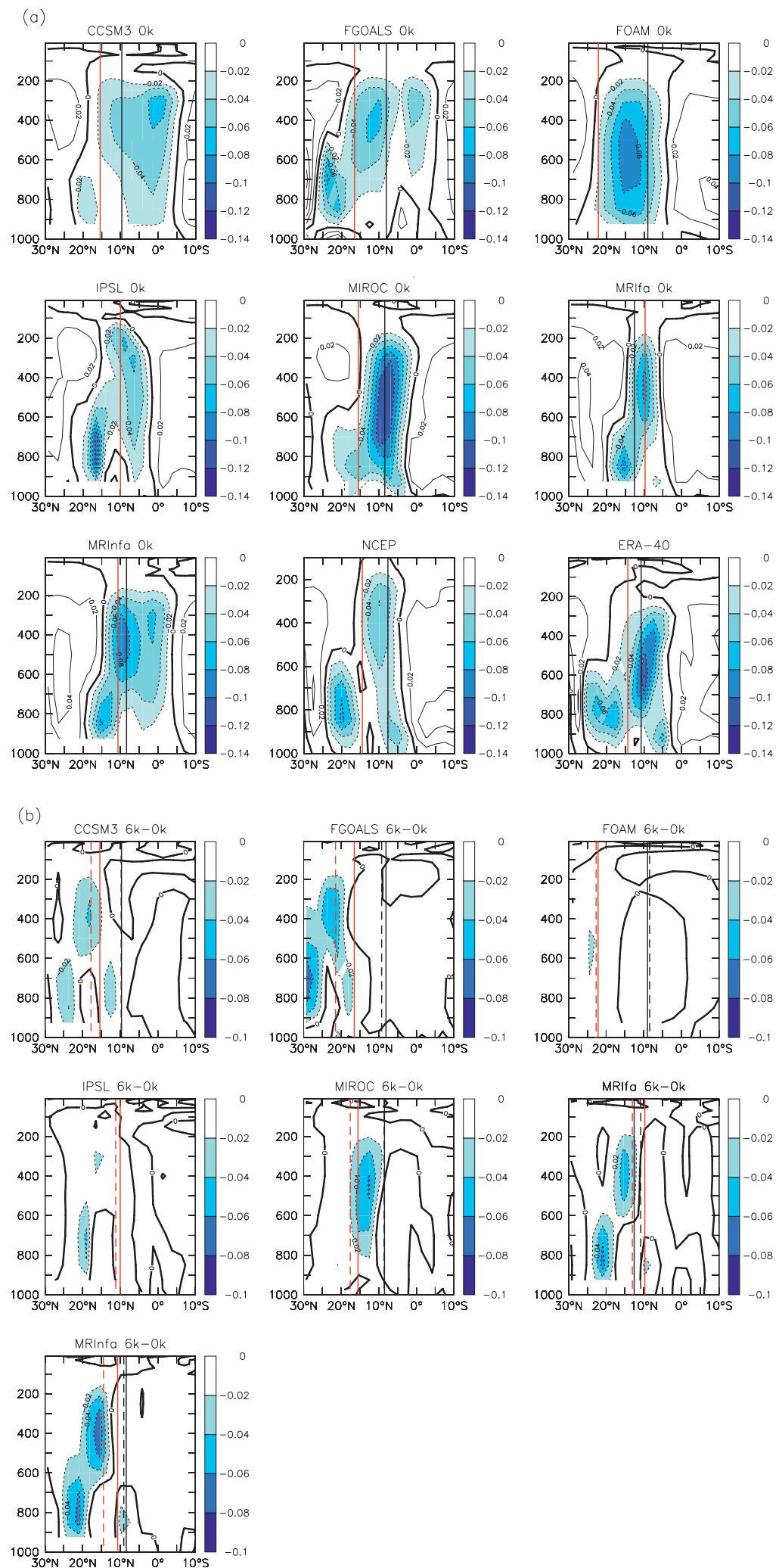

FIG. 4. Zonal average profiles of the vertical velocity $\left(\mathrm{Pa} \mathrm{s}^{-1}\right)$ plotted as a function of latitude between $10^{\circ} \mathrm{W}$ and $10^{\circ} \mathrm{E}$ averaged over July and August for the different models: (a) 0 ka and (b) $(6-0)$ ka. Red lines are for the African easterly jet at $600 \mathrm{hPa}$, and black lines are for the tropical easterly jet at $150 \mathrm{hPa}$. Solid lines are for $0 \mathrm{ka}$ and dashed ones are for $6 \mathrm{ka}$. 


\section{b. Precipitation and convective regimes in West Africa}

To analyze the behavior of the different models and to identify possible connections between the simulated changes of precipitation at $6 \mathrm{ka}$ and the characteristics of the control simulation, we adopt the framework proposed by Bony et al. (2004) to classify the model simulations into convective regimes. Although the classification was introduced to analyze cloud feedback and convection over the tropical oceans (Bony and Dufresne 2005), it is well suited to capturing the different convective regimes over West Africa. Considering the vertical circulation shown in Fig. 4, we then choose a region that covers the Sahel and southern Sahara $\left(7^{\circ}-25^{\circ} \mathrm{N}, 10^{\circ} \mathrm{W}-20^{\circ} \mathrm{E}\right)$ for the study of convective regimes. In this methodological framework, the total precipitation over this region can be computed as

$$
\operatorname{Pr}=\int_{-\infty}^{+\infty} \operatorname{Pr}_{\omega} P_{\omega} d \omega, \quad \int_{-\infty}^{+\infty} P_{\omega} d \omega=1
$$

where $\operatorname{Pr}_{\omega}$ is the precipitation within a given convective regime and $P_{\omega}$ is the normalized probability distribution function (PDF) for the July and August averaged $\omega 500$ that defines the convective regimes over the Sahel and southern Sahara (Fig. 5). For comparison with observations, we use the reanalyses to estimate the $500-\mathrm{hPa}$ vertical velocity, ground observations for temperature and precipitation, and satellite products for radiation. To simplify the discussions when comparing the simulated changes, the results are also summarized in three major convective regimes defined as deep convection $\left(\omega 500<-0.06 \mathrm{~Pa} \mathrm{~s}^{-1}\right)$, moderate convection $(\omega 500$ between -0.06 and $\left.0 \mathrm{~Pa} \mathrm{~s}^{-1}\right)$, and subsidence $(\omega 500>$ $0 \mathrm{~Pa} \mathrm{~s}^{-1}$ ). The limits of these three regimes were arbitrarily defined from Fig. 5 so as to highlight differences between models.

The normalized PDF for $\omega 500$ exhibits two peaks in the reanalyses (Fig. 5a). The first one around 0.01$0.02 \mathrm{~Pa} \mathrm{~s}^{-1}$ reflects the large subsidence area in the Sahara and the other around -0.04 to $-0.06 \mathrm{~Pa} \mathrm{~s}^{-1}$ corresponds to the convection associated with the rain belt. Deep convection only occurs in a small fraction of the study region. The range of regimes is narrower in NCEP than in ERA-40, and the extreme deep convection regimes found in ERA-40 do not occur in NCEP. The differences between the two reanalyses illustrate the uncertainty arising from the different convection schemes, the interactions with the different physical parameterizations, the assimilation schemes, and also the limited observational data that are used as inputs.
As shown in Figs. 5b-h, PMIP2 0-ka simulations fail to reproduce the two-peak PDF pattern found in the reanalyses. The models can be divided into three groups. 1) Three models [Community Climate System Model, version 3 (CCSM3), FGOALS, and IPSL] capture the two peaks but underestimate the subsidence in the Sahara. The convection in these models controls larger areas than in the reanalyses and the dry convection in the Sahara is too strong and extends too high, as shown in Fig. 4a. However, the maximum convection (negative peak) occurs in different regimes depending on the model. FGOALS has a larger PDF in the deep convective regime while CCSM3 and IPSL have maximum PDF in the moderate convective regime (Figs. 5b,c,e). 2) Three models [Model for Interdisciplinary Research on Climate (MIROC) and two Meteorological Research Institute (MRI) models] capture the subsidence peak in the Sahara but produce convective regimes that are uniformly distributed. These models also have a relatively larger PDF in the deep convective regime so that the range of convective regimes is broader than in group 1 (Figs. 5f-h). In these models, the convection scheme appears to be either on or off, with no intermediate behavior, and they therefore miss the moderate convective regimes. 3) The PDF in FOAM increases from subsidence toward convective regimes and the peak in the deep convective regime indicates the whole region is dominated by convective activities (Fig. 5d). However, we will not comment further on the results from FOAM because erroneous values were found in several data files stored in the PMIP2 database.

Several climate variables are plotted as a function of circulation regime in Fig. 6. As expected, the precipitation is nearly linearly related to $\omega 500$ but with different slopes depending on the models: from -51.3 in MRInfa to $-107.8 \mathrm{~mm} \mathrm{day}^{-1}\left(\mathrm{~Pa} \mathrm{~s}^{-1}\right)^{-1}$ in FOAM (Fig. 6a). For comparison we estimated these slopes using the reanalyses for $\omega 500$ and the CRU data for precipitation, and the slopes obtained for the moderate convective regime are $-79.2 \mathrm{~mm} \mathrm{day}^{-1}\left(\mathrm{~Pa} \mathrm{~s}^{-1}\right)^{-1}$ for the estimates with ERA-40 and $-104.7 \mathrm{~mm} \mathrm{day}^{-1}\left(\mathrm{~Pa} \mathrm{~s}^{-1}\right)^{-1}$ for the estimates with NCEP. This suggests that models with a larger negative slope are in better agreement with present-day climate observations. If all models had the same $\omega 500 \mathrm{PDF}$ for $0 \mathrm{ka}$, models with the larger negative slope would produce greater precipitation over the whole region. This would be the case for CCSM3, FOAM, IPSL, and MIROC. However, IPSL does not produce high precipitation at $0 \mathrm{ka}$ (Fig. 7a) because of the narrower PDF distribution and lower precipitation rate within the moderate convective regimes (Figs. 5e, 6a). Similarly, the two MRI versions have a smaller negative slope, which explains why they do not produce excessive precipitation 

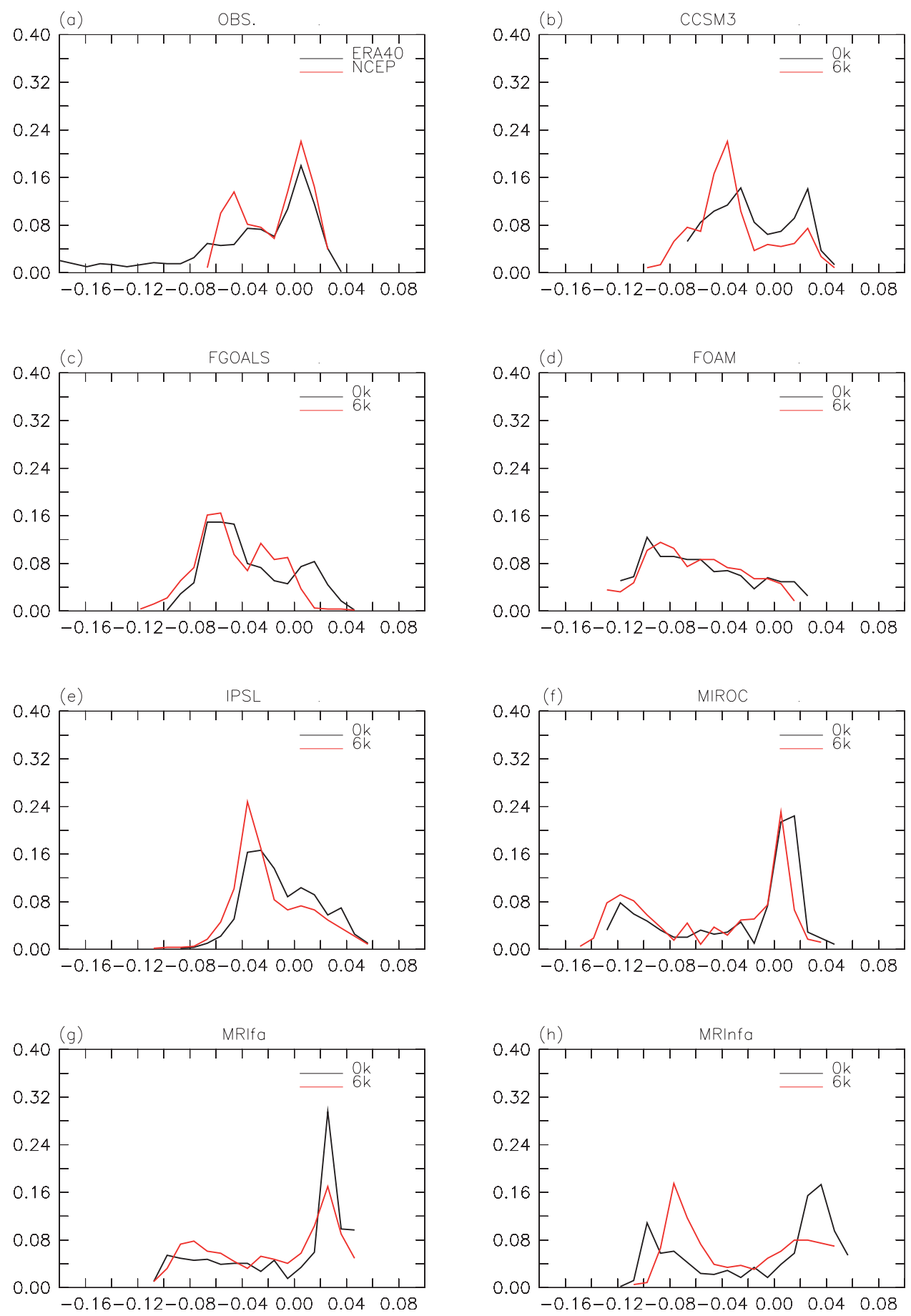

FIG. 5. Normalized PDF of $\omega 500$ averaged over July and August for (a) ERA-40 (black) and NCEP (red); (b)-(h) seven coupled models, where black lines are for $0 \mathrm{ka}$ and red lines for $6 \mathrm{ka}$. Intervals of the convective regimes are $0.01 \mathrm{~Pa} \mathrm{~s}^{-1}$.

rates for 0 ka (Fig. 7a), despite the fact that they reproduce the deeper convective regimes.

The analyses of TAS and the heat fluxes at the surface and TOA (Figs. 6b-h) are consistent with the PMIP2 model median as shown in Fig. 3a. This confirms that models overestimate solar radiation at the surface and underestimate temperature in the subsidence region due to a larger than observed longwave radiation and an overestimation of the sensible heat flux in some of the models. It further demonstrates that the surface HFLS 

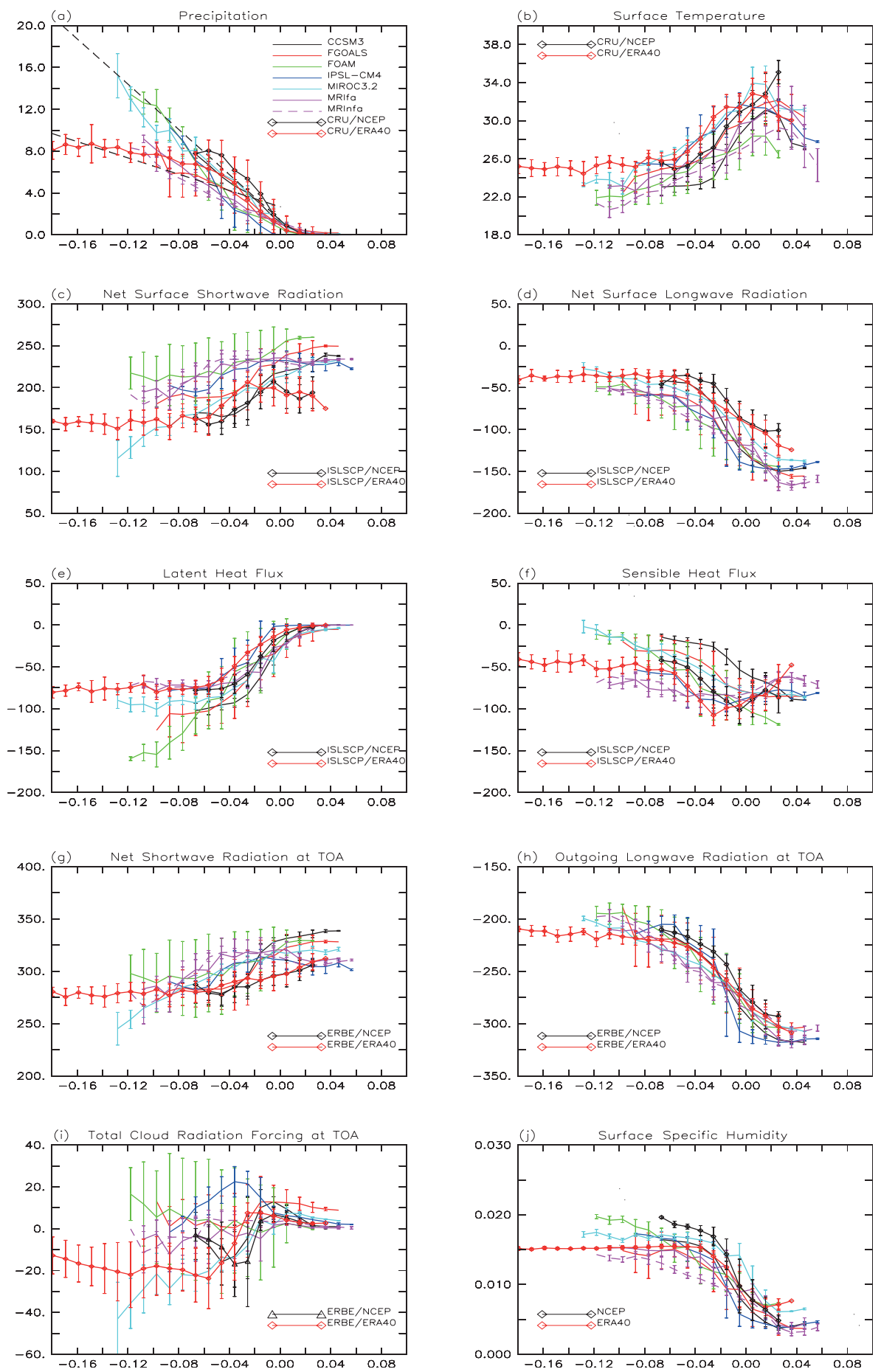

FIG. 6. Classification of the monsoonal variables on the convective regimes for $0 \mathrm{ka}$ for a subset of seven PMIP2 coupled models: (a) precipitation $\left(\mathrm{mm} \mathrm{day}^{-1}\right.$ ); (b) TAS $\left({ }^{\circ} \mathrm{C}\right)$; (c) RSS; (d) net RLS; (e) latent heat flux; (f) sensible heat flux; (g) net shortwave radiation at TOA; (h) outgoing longwave radiation at TOA; (i) total cloud radiation forcing at TOA; and (j) surface specific humidity $\left(\mathrm{kg} \mathrm{kg}^{-1}\right)$. Model results are compared with observations that correspond to a mixture of reanalyses, ground observations, and satellite products. In particular, the different observed variables are classified as a function of the vertical velocity in the reanalyses. The spread between the two reanalyses provides a rough estimate of the uncertainty in the classification. The precipitation and TAS are from CRU; the heat fluxes at surface and TOA are from ISLSCP and ERBE, respectively. The specific humidity data used are from NCEP and ERA-40. The units of the heat fluxes at TOA and surface and the cloud radiation forcing are $\mathrm{W} \mathrm{m} \mathrm{m}^{-2}$. 

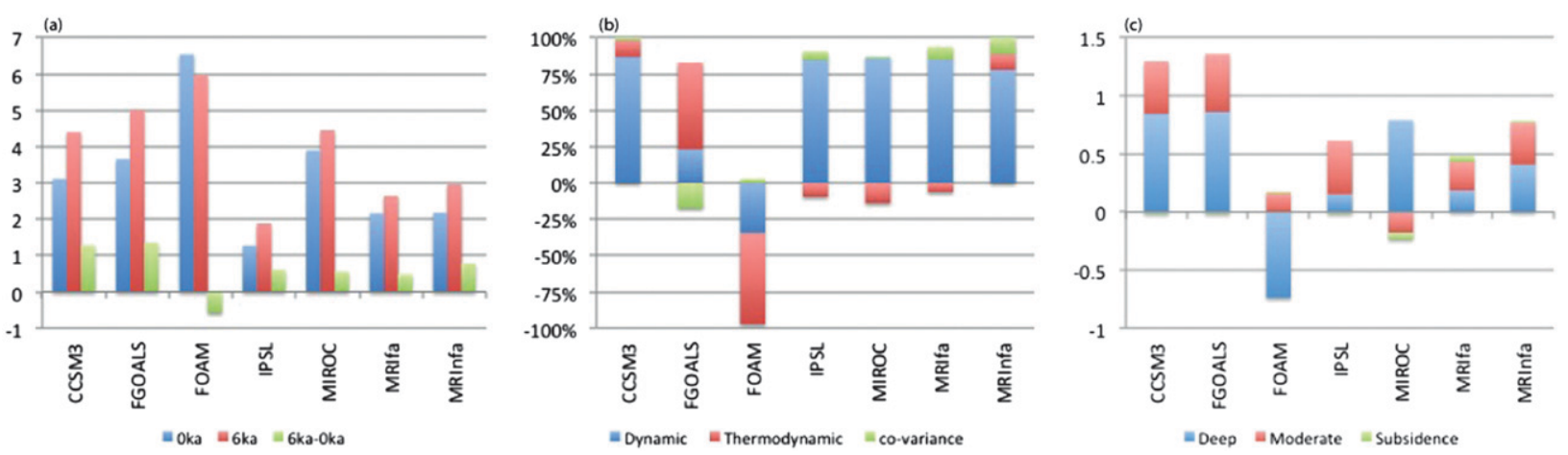

FIG. 7. (a) Precipitation and its change over the Sahel and southern Sahara $\left(7^{\circ}-25^{\circ} \mathrm{N}, 10^{\circ} \mathrm{W}-20^{\circ} \mathrm{E}\right)$ at $6 \mathrm{ka}\left(\mathrm{mm} \mathrm{day}^{-1}\right)$; (b) contributions of the large-scale circulation change (dynamic term), precipitation change in each regime (thermodynamic term), and the covariation of circulation with precipitation at $6 \mathrm{ka} \mathrm{( \% );} \mathrm{and} \mathrm{(c)} \mathrm{the} \mathrm{change} \mathrm{of} \mathrm{total} \mathrm{precipitation} \mathrm{within} \mathrm{three} \mathrm{major} \mathrm{convection} \mathrm{regimes} \mathrm{simplified} \mathrm{from}$ Fig. 5: the deep convection regime $\left(\omega 500<-0.06 \mathrm{~Pa} \mathrm{~s}^{-1}\right)$, moderate convection $\left(\omega 500\right.$ between -0.06 and 0 Pa s$\left.{ }^{-1}\right)$, and subsidence $\left(\omega 500>0 \mathrm{~Pa} \mathrm{~s}^{-1}\right)$.

varies nearly linearly with $\omega 500$ for the transition from subsidence to moderate convection regimes but is not a function of $\omega 500$ in deep convective regimes, which are mainly triggered by the large-scale convergence of humidity (Fig. 6j). Models with the larger negative slope between precipitation and $\omega 500$ in moderate convective regimes also have large surface latent heat flux in these regimes. This suggests that the evaporation and local surface conditions have a larger contribution in triggering the convection in these models or that the convection scheme is more efficient in drying the low-level atmosphere, thereby enhancing evaporation if soil moisture allows it. Note that IPSL has a deficit of evaporation that is certainly due to excessive dry soils, which explains the deficit in simulated precipitation. FGOALS still exhibits linear variations between HFLS and $\omega 500$ in the deep convective regime (Fig. 6e), suggesting that its coupling between evaporation, convection, and precipitation is too strong.

Substantial differences between the models are also found in the total cloud radiation forcing at TOA in deep and moderate convective regimes (Fig. 6i). They contribute to the model spread found in the simulated meridional temperature gradient between subsidence and deep convection regimes, as well as in the response of surface temperature to the mid-Holocene insolation forcing. Those models that have the larger cloud radiation forcing produce the larger surface temperature gradient between the Sahara region and the core of the rain belt (Fig. 6b).

\section{c. Changes during the mid-Holocene and link with modern characteristics}

All models, except FOAM, give an increased total amount of precipitation over the region of the Sahel and southern Sahara $\left(7^{\circ}-25^{\circ} \mathrm{N}, 10^{\circ} \mathrm{W}-20^{\circ} \mathrm{E}\right)$ at $6 \mathrm{ka}$, as shown in Fig. 7a. The total change in precipitation for $6 \mathrm{ka}$ can be further decomposed as follows:

$$
\begin{aligned}
\delta \operatorname{Pr}= & \int_{-\infty}^{+\infty} \operatorname{Pr}_{\omega} \delta P_{\omega} d \omega+\int_{-\infty}^{+\infty} P_{\omega} \delta \operatorname{Pr}_{\omega} d \omega \\
& +\int_{-\infty}^{+\infty} \delta \operatorname{Pr}_{\omega} \delta P_{\omega} d \omega .
\end{aligned}
$$

The three terms on the right-hand side were computed for each model from the regime-sorted analyses. The results show that in most of the models (except FGOALS and FOAM) the change of precipitation mainly results from the changes in PDF (dynamic term, the first term on the right-hand side), while the changes of rainfall within each regime (thermodynamic term, the second term) and the covariance between these two effects (the third term) have relatively small but nonnegligible contributions (Fig. 7b). In all the simulations but FOAM, the dynamical change is characterized by an increase of deep and moderate convective regimes and a reduction of subsidence regimes as shown in Fig. 7c. This confirms the results of Zhao et al. (2005), who considered precipitation and precipitation minus evaporation over the Sahel region. This finding implies that the increased precipitation mainly results from a higher frequency of high precipitating events, as shown from the atmosphere-only simulation of de Noblet et al. (1996). In addition, for a similar shift in $\omega 500$ PDF, models that have a larger negative slope of precipitation as a function of the convective regimes would produce larger precipitation changes.

However, systematic differences can be found between the different model categories. Models in group 1 (CCSM3, FGOALS, and IPSL) show a reduction of 

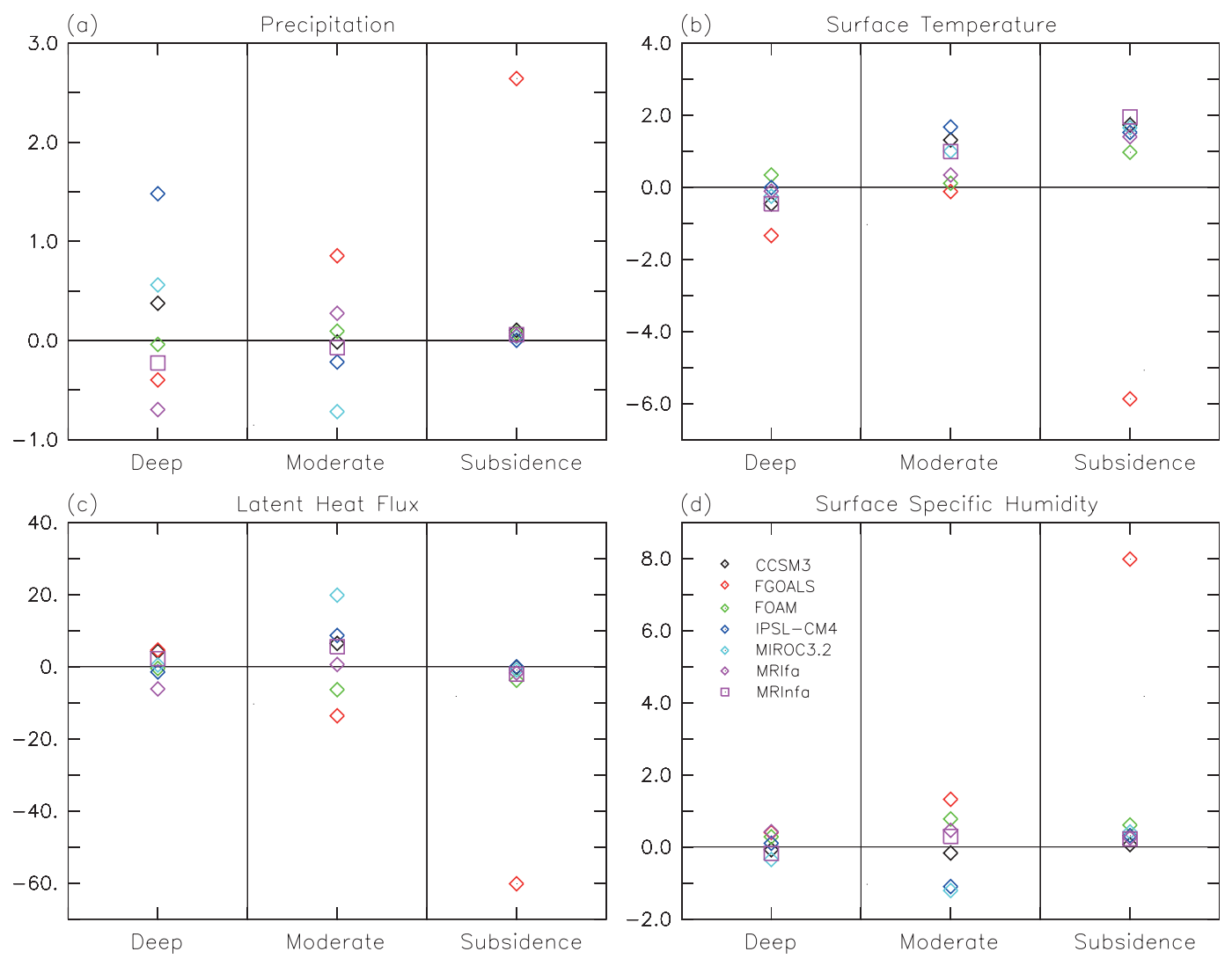

FIG. 8. Changes of monsoonal variables in the mid-Holocene within the three major convective regimes for the seven model subset of the PMIP2 models: (a) precipitation $\left(\mathrm{mm} \mathrm{day}^{-1}\right),(\mathrm{b})$ TAS $\left({ }^{\circ} \mathrm{C}\right)$, (c) latent heat flux, and (d) specific humidity $\left(\mathrm{kg} \mathrm{kg}^{-1}\right)$. The three major convective regimes are as in Fig. 7.

subsidence and increases in the deep and moderate convective regimes with a shift toward regimes that are not present in the control simulation (Figs. 5b,c,e, 7c). In these models, large-scale temperature gradients and shears over Africa and the increase in atmospheric moisture convergence appear as dominant factors in triggering deeper convection and higher precipitation. Among the models of group 2, which capture the subsidence peak but with uniformly distributed convective regimes, MIROC shows a shift of PDF toward deep convective regimes but with little change of PDF in moderate convective regimes (Fig. 5f), while the two MRIs have a redistribution of the PDF between the different regimes but with no shift toward deeper convective regimes that are not present in the control simulation (Fig. $5 \mathrm{~g}, \mathrm{~h}$ ). This may be because convection and precipitation are already driven by these deep convective regimes in the 0 -ka simulation.

The total change in precipitation in the different regimes (Fig. 7c) is also affected by the thermodynamic changes (Fig. 8). In this respect, FGOALS differs from the other models in group 1 , since it is the only model for which the precipitation change for $6 \mathrm{ka}$ is dominated by the thermodynamic term (Fig. 7b), suggesting that a threshold was reached in this model. The northward shift of the monsoon circulation triggers local hydrological recycling that increases the evaporation, particularly in the subsidence regime (Fig. 8d), thus favoring the strengthening of precipitation and latent heat release (Fig. 8c) and TAS cooling (Fig. 8b). This also implies the occurrence of extreme precipitation events in the subsidence regime in the southern Sahara in FGOALS.

Three other models (IPSL, MIROC, and MRIfa) also exhibit less efficient convective regimes in which the precipitation is reduced at $6 \mathrm{ka}$. The total precipitation shows an increase (Fig. 7c) in these models because these less efficient regimes occur over a wider area. It is difficult to fully understand why the regimes are less efficient in these models from the variables provided in the PMIP2 database. The reduction in precipitation is greater in the deep convective regime for MRIfa (Fig. 8a), but there is no direct link with surface fluxes or specific humidity, suggesting that it results from a broader humidification of the atmospheric column. For IPSL and 
(a)

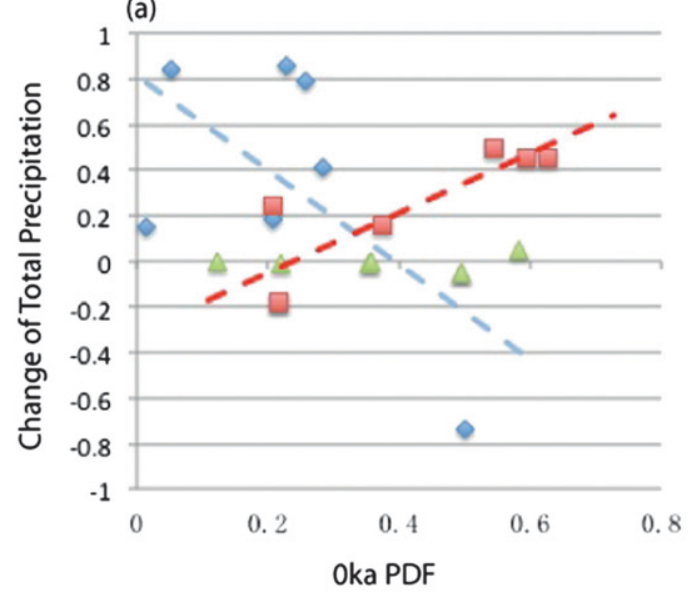

(b)

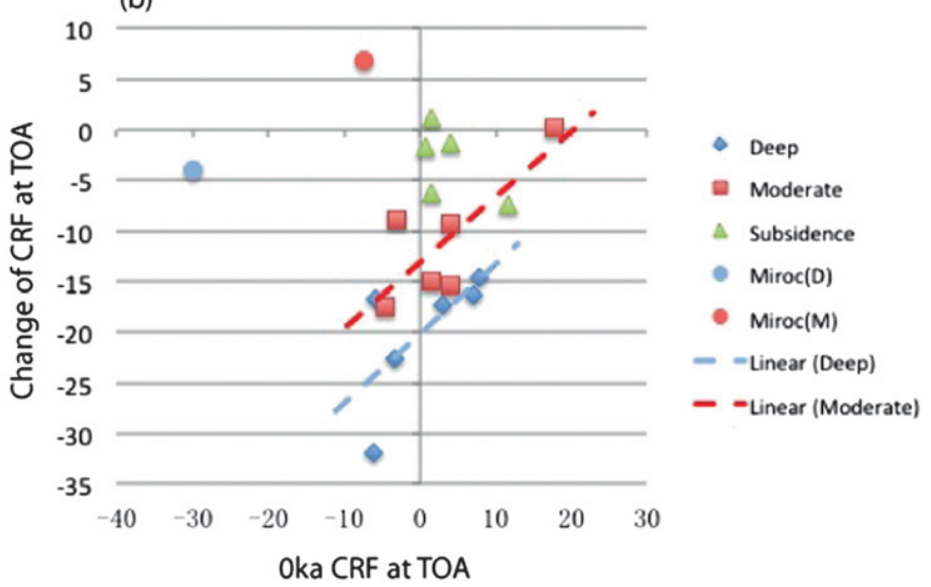

FIG. 9. Within the three major convective regimes across the models: (a) the change of total precipitation ( $\left.\mathrm{mm}^{\mathrm{day}}{ }^{-1}\right)$ at $6 \mathrm{ka}$ as a function of the PDF of $\omega 500$ in the 0 -ka simulation and (b) the change of cloud radiation forcing (CRF) at TOA (W $\mathrm{m}^{-2}$ ) as a function of its value in the modern climate simulation. Results for MIROC are highlighted in (b), because they do not support the relationship found from the other simulations.

MIROC the reduction is greater in moderate convective regimes and is associated with higher surface temperature and reduced evaporation and latent heat flux (Fig. 8).

Figure $9 \mathrm{a}$ also highlights an inverse relationship between precipitation at $6 \mathrm{ka}$ within the deep convective regimes and the relative importance of this regime in the control simulation: the larger the fraction in the control simulation, the larger the reduction of precipitation within the regime. This explains why Braconnot et al. (2007b) found an inverse relationship between the percentage total precipitation change over West Africa and the amount of precipitation simulated for present-day climate across PMIP2 simulations.

\section{Discussion and conclusions}

In this study, simulations of the West African monsoon from PMIP2 coupled models for both present-day climate and the mid-Holocene are assessed and the model spread is discussed based on a classification of the monsoonal convective regimes. PMIP2 model median values for the monsoon rainfall, TAS, and the radiation and heat fluxes at TOA are compared with two reanalyses and observations from CRU, ERBE, and ISLSCP satellite data, as well as past climate reconstructions for precipitation. This comparison shows that the PMIP2 model ensemble provides a reasonable picture of climatology for both the present-day and mid-Holocene that can be used as climate input for different environmental studies.

However, systematic model biases are highlighted in the preindustrial simulations. In particular, meridional temperature gradient is underestimated between $0^{\circ}$ and $20^{\circ} \mathrm{N}$ by the PMIP 2 model median, resulting in a smaller gradient of SLP between the Gulf of Guinea and Sahel. This explains a lower than observed low-level moisture flux and an underestimate of rainfall intensity when compared with observations. This underestimate of the temperature gradient results mainly from too low a temperature over the Sahara, in spite of excessive solar radiation at TOA and the surface. The other fluxes are also stronger than the satellite data, in particular the longwave flux at the surface.

The PMIP2 model median for the mid-Holocene shows increases of precipitation over the Sahel and the southern Sahara due to a northward shift of the ITCZ in response to an enhanced seasonal cycle in the Northern Hemisphere. The change of precipitation is consistent with proxy data, even though the northward extent of the rain belt and the intensity of precipitation change are underestimated. The analyses of convective regimes in a subset of seven PMIP2 models confirm that the differences between the mid-Holocene and present-day climates are mainly driven by the large-scale dynamics. The increased convergence of humidity over the Sahel and the southern Sahara resulting from the strengthened monsoon flow triggers deeper convection and increases the precipitation. It also allows for a northward extension of the rain belt, which reduces the PDF for areas of subsidence. Only two models, FGOALS and FOAM, produce changes that are driven by the changes in atmospheric thermodynamics. However, the results of these two models should be considered with care, since they differ in several respects from both the other models and the modern climatology inferred from the reanalysis data and observations. FGOALS has an increase of 
precipitation in subsidence regions, suggesting local or large-scale condensation and extreme precipitation events there. FOAM is the only model that produces a reduction of total precipitation over the Sahel and southern Sahara region.

For the other models, the changes of precipitation are tied to present-day climate conditions (precipitation as a function of the convective regimes) and to the changes in the distribution of precipitation. Even though there is a large spread between model results, two major model categories emerge from this analysis. Models for which deep convective regimes are dominant in present-day climate mainly have a higher frequency of high precipitation events, with little or no shift toward regimes of deeper convection. For this category the deep convective regimes are less efficient, which partially counteracts the increase in precipitation. Models that favor moderate convection as in the present-day climate reanalyses produce a shift of the convective regime distribution toward deeper convection, and all convective regimes become more efficient in producing precipitation. The comparison of the different regimes with present-day observations estimated by $\omega 500$ from the reanalyses suggests that models in the latter category are better at reproducing the distribution of convective regimes over West Africa.

It is thus important to go back to the large-scale circulation and to understand how the large-scale temperature gradients are modified and where the most sensitive regions are located in order to fully understand the differences in the changes during mid-Holocene. This matches the conclusion of Braconnot et al. (2002), who found that large-scale changes and the thermodynamic factors inferred from present-day climate simulation are both needed to account for the large spread of model simulations in the monsoon area. Assessment of the radiation and heat fluxes over West Africa in the models is difficult given the large uncertainties in the reanalyses and observations, but the results clearly show that the models overestimate the solar radiation (Fig. 3a) and underestimate the cloud radiative forcing in deep and moderate convective regimes (Fig. 6i). These biases also have a damping effect on the enhancement of the mid-Holocene temperature gradient over the continent and the strengthening of the African heat low in summer and hence the inland penetration of the monsoon flow.

The differences in the cloud radiative forcing between the deep convection within the ITCZ and the subsidence farther north have a direct impact on the transmission of the insolation forcing from the top of the atmosphere to the land surface. This is supported by the linear relationship found across model results between the change in cloud radiative forcing for $6 \mathrm{ka}$ and the cloud radiative forcing estimate in the present-day climate for both the deep and moderate convection regimes (Fig. 9b). This indicates that the albedo effect of clouds depends on the simulation of present-day climate for most of the models, thereby emphasizing the need to improve the representation of cloud forcing to improve modeling of the large-scale monsoon flow over West Africa.

It is not possible from this analysis to isolate completely the role of the convection scheme from the interaction with the land surface or soil moisture. This would require running additional sensitivity experiments to separate the different contributions (convection, clouds, albedo, soil moisture, vegetation, etc.). Different land surface schemes produce significantly different surface fluxes over most land. Wei et al. (2010) suggested that the differences in atmospheric parameterization and in land surface scheme give comparable changes to the sensible heat flux over semiarid regions. Our analyses show that some of the models have too strong a coupling between the latent heat and convection in deep convective regimes. They also highlight the key role of local hydrological recycling in moderate convection, suggesting that a proper representation of soil moisture is needed and that it is particularly important in the transition region between moderate convection and subsidence, such as the Sahara-Sahel transition.

The classification into convective regimes is shown here to be very useful for classifying the different model responses and isolating some aspects of the control climate; these include the distribution of convective regimes, the amount of precipitation within different regimes, or the cloud radiative forcing that play a role in the simulated response and explain part of the model spread. This study provides a framework for understanding model results that can be applied to different climate and scenario simulations, including projections of future climate.

Acknowledgments. We acknowledge the international modeling groups for providing their data for analysis and the Laboratoire des Sciences du Climat et de l'Environnement (LSCE) for collecting and archiving the model data. The PMIP2 data archive is supported by CEA and CNRS. More information is available online (at http://pmip2.lsce.ipsl.fr). Our analyses have benefited from fruitful discussions with Sandrine Bony (LMD, France), Frederic Hourdin (LMD, France), and Françoise Guichard (CNRM, France). Dr. Zheng was supported by the National Agency for Research in France (project ANR-vulnerability "SAHELP") in performing analyses at LSCE/CNRS and was jointly supported by the National Basic Research Program of 
China (Grant 2010CB950502) the "Strategic Priority Research Program Climate Change: Carbon Budget and Relevant Issues" of the Chinese Academy of Sciences (Grant XDA05110301) to complete the study at LASG/ IAP, China.

\section{REFERENCES}

Anderson, P. M., and Coauthors, 1988: Climatic changes of the last 18,000 years: Observations and model simulations. Science, 241, 1043-1052.

Barkstrom, B. R., 1984: The Earth Radiation Budget Experiments (ERBE). Bull. Amer. Meteor. Soc., 65, 1170-1185.

Bartlein, P. J., and Coauthors, 2011: Pollen-based continental climate reconstructions at 6 and $21 \mathrm{ka}$ : A global synthesis. Climate Dyn., 37, 775-802, doi:10.1007/s00382-00010-00904-00381.

Bony, S., and J.-L. Dufresne, 2005: Marine boundary layer clouds at the heart of tropical cloud feedback uncertainties in climate models. Geophys. Res. Lett., 32, L20806, doi:10.1029/ 2005 GL023851.

,-- H. L. Treut, J.-J. Morcrette, and C. Senior, 2004: On dynamic and thermodynamic components of cloud changes. Climate Dyn., 22, 71-86.

Braconnot, P., S. Joussaume, N. D. Noblet, and G. Ramstein, 2000: Mid-Holocene and Last Glacial Maximum African monsoon changes as simulated within the Paleoclimate Modelling Intercomparison Project. Global Planet. Change, 26, 51-66.

_ M. Loutre, B. Dong, S. Joussaume, and P. Valdes, 2002: How the simulated change in monsoon at $6 \mathrm{ka} \mathrm{BP}$ is related to the simulation of the modern climate: Results from the Paleoclimate Modeling Intercomparison Project. Climate Dyn., 19, 107-121.

_ , and Coauthors, 2004: Evaluation of PMIP coupled oceanatmosphere simulations of the mid-Holocene. Past Climate Variability through Europe and Africa, R. W. Battarbee, F. Gasse, and C. E. Stickley, Eds., Springer, 515-533.

— and Coauthors, 2007a: Results of PMIP2 coupled simulations of the mid-Holocene and Last Glacial Maximum-Part 1: Experiments and large-scale features. Climate Past, 3, 261277.

__ , and Coauthors, 2007b: Results of PMIP2 coupled simulations of the mid-Holocene and Last Glacial MaximumPart 2: Feedbacks with emphasis on the location of the ITCZ and mid- and high latitudes heat budget. Climate Past, 3, 279-296.

Coe, M. T., and S. P. Harrison, 2002: The water balance of northern Africa during the mid-Holocene: An evaluation of the $6 \mathrm{ka} \mathrm{BP}$ PMIP simulations. Climate Dyn., 19, 155-166.

Cook, K. H., 1999: Generation of the African easterly jet and its role in determining West African precipitation. J. Climate, 12, $1165-1184$.

_ _ and E. K. Vizy, 2006: Coupled model simulations of the West African monsoon system: Twentieth- and twenty-first-century simulations. J. Climate, 19, 3681-3703.

de Noblet, N., P. Braconnot, S. Joussaume, and V. Masson, 1996: Sensitivity of simulated Asian and African summer monsoons to orbital induced variations in insolation 12,115 and $6 \mathrm{kBP}$. Climate Dyn., 12, 589-603.

Dolman, A., J. Gash, J. Goutorbe, Y. Kerr, T. Lebel, S. Prince, and J. Stricker, 1997: The role of the land surface in Sahelian climate: HAPEX-Sahel results and future research needs. J. Hydrol., 188, 1067-1079.
Fontaine, B., S. Louvet, and P. Roucou, 2007: Fluctuations in annual cycles and inter-seasonal memory in West Africa: Rainfall, soil moisture and heat fluxes. Theor. Appl. Climatol., 88, $57-70$.

Gasse, F., 2002: Diatom-inferred salinity and carbonate oxygen isotopes in Holocene waterbodies of the western Sahara and Sahel (Africa). Quat. Sci. Rev., 21, 737-767.

Giannini, A., R. Saravanan, and P. Chang, 2003: Oceanic forcing of Sahel rainfall on interannual to interdecadal time scales. Science, 302, 1027-1030.

Gordon, C., C. Cooper, C. A. Senior, H. Banks, J. M. Gregory, T. C. Johns, J. F. B. Mitchell, and R. A. Wood, 2000: The simulation of SST, sea ice extents and ocean heat transport in a version of the Hadley Centre coupled model without flux adjustments. Climate Dyn., 16, 147-168.

Guichard, F., L. Kergoat, E. Mougin, F. Timouk, F. Baup, P. Hiernaux, and F. Lavenu, 2009: Surface thermodynamics and radiative budget in the Sahelian Gourma: Seasonal and diurnal cycles. J. Hydrol., 375, 161-177.

Hély, C., P. Braconnot, J. Watrin, and W. Zheng, 2009: Climate and vegetation: Simulating the African humid period. C. R. Geosci., 341, 671-688.

Jacob, R., C. Schafer, I. Foster, M. Tobis, and J. Andersen, 2001: Computational design and performance of the Fast Ocean Atmosphere Model, version 1. Proc. Int. Conf. on Computational Science, San Francisco, CA, American Mathematical Society, 175-184.

Janicot, S., 1992: Spatiotemporal variability of West African rainfall. Part II: Associated surface and airmass characteristics. J. Climate, 5, 499-511.

Jolly, D., and Coauthors, 1998a: Biome reconstruction from pollen and plant macrofossil data for Africa and the Arabian Peninsula at 0 and 6000 years. J. Biogeogr., 25, 1007-1027.

_ S. P. Harrison, B. Damnati, and R. Bonnefille, 1998b: Simulated climate and biomes of Africa during the late Quaternary: Comparison with pollen and lake status data. Quat. Sci. Rev., 17, 629-657.

Joussaume, S., and K. Taylor, 1995: Status of the Paleoclimate Modeling Intercomparison Project (PMIP). Proceedings of the First International AMIP Scientific Conference, WMO/ TD-732, WCRP-92, 425-430.

, and Coauthors, 1999: Monsoon changes for 6000 years ago: Results of 18 simulations from the Paleoclimate Modeling Intercomparison Project (PMIP). Geophys. Res. Lett., 26, 859862.

Jungclaus, J., and Coauthors, 2006: Ocean circulation and tropical variability in the coupled model ECHAM5/MPI-OM. J. Climate, 19, 3952-3972.

K-1 Model Developers, 2004: K-1 coupled GCM (MIROC) description. CCSR/NIES/FRCGC K-1 Tech. Rep. 1, 39 pp.

Kållberg, P., 1997: Aspects of the re-analysed climate. ECMWF Re-Analysis Final Rep. 2, 89 pp.

Kalnay, E., and Coauthors, 1996: The NCEP/NCAR 40-Year Reanalysis Project. Bull. Amer. Meteor. Soc., 77, 437-471.

Kohfeld, K. E., C. L. Quere, S. P. Harrision, and R. F. Andersen, 2005: Role of marine biology in glacial-interglacial $\mathrm{CO}_{2}$ cycles. Science, 308, 74-78.

Kutzbach, J. E., and B. L. Otto-Bliesner, 1982: The sensitivity of the African-Asian monsoon climate to orbital parameter changes for 9000 years B.P. in a low-resolution general circulation model. J. Atmos. Sci., 39, 1177-1188.

- and P. J. Guetter, 1986: The influence of changing orbital parameters and surface boundary conditions on climate 
simulations for the past 18000 years. J. Atmos. Sci., 43, 1726-1759.

_ , and Z. Liu, 1997: Response of the African monsoon to orbital forcing and ocean feedbacks in the middle Holocene. Science, 278, 440-443.

Lézine, A. M., W. Zheng, P. Braconnot, and G. Krinner, 2011: Late Holocene plant and climate evolution at Lake Yoa, northern Chad: Pollen data and climate simulations. Climate Past, 7, 1351-1362.

Mallet, M., and Coauthors, 2008: Aerosol direct radiative forcing over Djougou (northern Benin) during the African Monsoon Multidisciplinary Analysis dry season experiment (special observation period-0). J. Geophys. Res., 113, D00C01, doi:10.1029/2007JD009419.

Marsland, S. J., J. Haak, J. H. Jungclaus, M. Latif, and F. Röske, 2003: The Max-Planck-Institute global ocean/sea ice model with orthogonal curvilinear coordinates. Ocean Modell., 5, 91127.

Marti, O., and Coauthors, 2010: Key features of the IPSL ocean atmosphere model and its sensitivity to atmospheric resolution. Climate Dyn., 34, 1-26.

Mitchell, J. F. B., 1990: Greenhouse warming: Is the mid-Holocene a good analogue? J. Climate, 3, 1177-1192.

Mitchell, T. D., and P. D. Jones, 2005: An improved method of constructing a database of monthly climate observations and associated high-resolution grids. Int. J. Climatol., 25, 693-712.

Nicholson, S., 2000: Land surface processes and Sahel climate. Rev. Geophys., 38, 117-140.

- 2009: A revised picture of the structure of the "monsoon" and land ITCZ over West Africa. Climate Dyn., 32, 1155-1171, doi:10.1007/s00382-008-0514-3.

Ohgaito, R., and A. Abe-Ouchi, 2009: The effect of sea surface temperature bias in the PMIP2 AOGCMs on mid-Holocene Asian monsoon enhancement. Climate Dyn., 33, 975-983.

Otto-Bliesner, B., E. Brady, G. Clauzet, R. Tomas, S. Levis, and Z. Kothavala, 2006: Last Glacial Maximum and Holocene climate in CCSM3. J. Climate, 19, 2526-2544.

Peyron, O., D. Jolly, P. Braconnot, R. Bonnefille, J. Guiot, D. Wirrmann, and F. Chalié, 2006: Quantitative reconstructions of annual rainfall in Africa 6000 years ago: Model-data comparison. J. Geophys. Res., 111, D24110, doi:10.1029/ 2006JD007396.

Phipps, S. J., 2006: The CSIRO Mk3L climate system model. Antarctic Climate and Ecosystems Cooperative Research Centre Tech. Rep. 3, 237 pp.

Poccard, I., S. Janicot, and P. Camberlin, 2000: Comparison of rainfall structures between NCEP/NCAR reanalyses and observed data over tropical Africa. Climate Dyn., 16, $897-$ 915.

Renssen, H., H. Goosse, T. Fichefet, V. Brovkin, E. Driesschaert, and F. Wolk, 2005: Simulating the Holocene climate evolution at northern high latitudes using a coupled atmosphere-sea iceocean-vegetation model. Climate Dyn., 24, 23-43.

Schmidt, G. A., and Coauthors, 2006: Present-day atmospheric simulations using GISS ModelE: Comparison to in situ, satellite, and reanalysis data. J. Climate, 19, 153-192.

Smith, E. A., 1998: The first ISLSCP field experiment. J. Atmos. Sci., 55, 1089-1090.

Solomon, S., D. Qin, M. Manning, M. Marquis, K. Averyt, M. M. B. Tignor, H. L. Miller Jr., and Z. Chen, Eds., 2007: Climate Change 2007: The Physical Science Basis. Cambridge University Press, 996 pp.

Texier, D., N. De Noblet, and P. Braconnot, 2000: Sensitivity of the African and Asian monsoons to mid-Holocene insolation and data-inferred surface changes. J. Climate, 13, 164-181.

Thorncroft, C. D., and M. Blackburn, 1999: Maintenance of the African easterly jet. Quart. J. Roy. Meteor. Soc., 125, 763786.

Uppala, S. M., and Coauthors, 2005: The ERA-40 Re-Analysis. Quart. J. Roy. Meteor. Soc., 131, 2961-3012.

Wei, J. F., P. Dirmeyer, Z. C. Guo, and L. Zhang, 2010: How much do different land models matter for climate simulation? Part I: Climatology and variability. J. Climate, 23, 3120-3134.

Xue, Y., and Coauthors, 2010: Intercomparison and analyses of the climatology of the West African monsoon in the West African Monsoon Modeling and Evaluation project (WAMME) first model intercomparison experiment. Climate Dyn., 35, 3-27.

Yu, Y., X. H. Zhang, and Y. F. Guo, 2004: Global coupled oceanatmosphere general circulation models in LASG/IAP. $A d v$. Atmos. Sci., 21, 444-455.

Yukimoto, S., and Coauthors, 2006: Present-day climate and climate sensitivity in the Meteorological Research Institute Coupled GCM version 2.3 (MRI-CGCM2.3). J. Meteor. Soc. Japan, 84, 333-363.

Zhao, Y., and Coauthors, 2005: A multi-model analysis of the role of the ocean on the African and Indian monsoon during the mid-Holocene. Climate Dyn., 25, 777-800.

— , P. Braconnot, S. P. Harrison, P. Yiou, and O. Marti, 2007: Simulated changes in the relationship between tropical ocean temperature and the western African monsoon during the mid-Holocene. Climate Dyn., 28, 533-551.

Zhou, T., and R. Yu, 2006: Twentieth-century surface air temperature over China and the globe simulated by coupled climate models. J. Climate, 19, 5843-5858. 